\title{
Safety of treatment with biologics for psoriasis in daily practice: 5 -year data
}

\author{
PPM Van Lümig*, RJB Driessen, MAM Berends, J B Boezeman, PCM van de Kerkhof, EMGJ de Jong \\ From 5th European Workshop on Immune-Mediated Inflammatory Diseases \\ Sitges-Barcelona, Spain. 1-3 December 2010
}

\section{Introduction}

The safety of biological treatment for psoriasis is an important issue. Concerns exist about a possible increased risk of cancer, including nonmelanoma skin cancer and lymphomas in psoriasis patients treated with TNF- $\alpha$ inhibitors [1]. Dermatological conditions have been shown to be a significant and clinically important problem in rheumatoid arthritis patients receiving TNF- $\alpha$ blocking therapy [2].

\section{Aim}

To prospectively evaluate the 5 -year safety of biological treatment for psoriasis in daily practice.

\section{Patients and methods}

A cohort of 173 psoriasis patients on biologics was prospectively followed for 5 years [3]. All adverse events reported were documented and analysed. Primary endpoint was the percentage of patients reporting at least one serious adverse event. The rate of malignancies, serious infections and serious cardiovascular events was compared to the general population incidence rate [4]. The nature and rate of dermatological adverse events was compared with a group of prospectively followed rheumatoid arthritis patients on TNF- $\alpha$ blocking therapy [2].

\section{Results}

Between February 2005 and April 2010173 patients were enrolled in the registry and went through a total number of 263 treatment episodes. The total number of patient years of follow-up in the registry was 409 . The number of patient years was the highest for etanercept. Forty-nine patients (28\%) reported 88 serious adverse events. Only one serious adverse event was certainly causally related to the biologic and twenty-one events (24\% of SAEs) were considered possibly related. The incidence of malignancies, serious infections and serious cardiovascular events was comparable to the population incidence rate, except for skin malignancies. The incidence of skin malignancies was significantly higher than the general population incidence rate. The nature and rate of dermatological adverse events differed from the rheumatoid arthritis cohort.

\section{Conclusion}

In this cohort the safety of biological therapies for psoriasis was favorable with a low incidence of therapy-related serious adverse events.

\section{Published: 25 November 2010}

\section{References}

1. Patel RV, Clark LN, Lebwohl M, Weinberg JM: Treatments for psoriasis and the risk of malignancy. J Am Acad Dermatol 2009, 60:1001-1017.

2. Flendrie M, Vissers WH, Creemers MC, de Jong EM, van de Kerkhof PC, van Riel PL: Dermatological conditions during TNF-alpha-blocking therapy in patients with rheumatoid arthritis: a prospective study. Arthritis Res Ther 2005, 7:R666-R676

3. Driessen RJ, Boezeman JB, van de Kerkhof PC, de Jong EM: Three-year registry data on biological treatment for psoriasis: the influence of patient characteristics on treatment outcome. Br J Dermatol 2009, 160:670-675.

4. van Weel C: The Continuous Morbidity Registration Nijmegen: background and history of a Dutch general practice database. Eur J Gen Pract 2008, 14(Suppl 1):5-12.

doi:10.1186/1479-5876-8-S1-P16

Cite this article as: Van Lümig et al:: Safety of treatment with biologics for psoriasis in daily practice: 5-year data. Journal of Translational Medicine 2010 8(Suppl 1):P16. 